\title{
The Study of Natural Solution Protective Activity on H7N9 Virus
}

\author{
Edward Krizhanovsky ${ }^{1}$, Lim Kwong Choong ${ }^{2}$, Natalya Laskova ${ }^{3}$ \\ ${ }^{1}$ Moscow Technical University of Communications and Informatics, Moscow, Russia \\ ${ }^{2}$ BAE International Inc. SDN BHD, Kuala-Lumpur, Malaysia \\ ${ }^{3}$ Saint-Petersburg State University of Telecommunications, Saint-Petersburg, Russia \\ Email: ekrizhanovsky@gmail.com
}

Received 19 March 2015; accepted 21 April 2015; published 23 April 2015

Copyright (C) 2015 by authors and Scientific Research Publishing Inc.

This work is licensed under the Creative Commons Attribution International License (CC BY). http://creativecommons.org/licenses/by/4.0/

(c) (i) Open Access

\section{Abstract}

Background: One of potentially dangerous problems for a human organism is the new strain of a virus of bird flu-A/H7N9. As it is regular mutation of bird flu virus, it obvious, that of antibacterial preparations is not efficient. Efficiency decreases when the number of agents with multiple stability to antimicrobic remedy vastly increases, the part of associate infections enlarges, and aggression of opportunistic pathogenic flora rises. This reduces the role of the preparations in prevention of epidemics. Therefore, the optimization of only etiotropic therapies does not fully solve the problem. In this connection natural preparations seem extremely promising which strengthen the functional condition of immune system and, thereby, activate protective forces of macroorganism. Objectives: One of such preparations is BAE Synergy Liquid, a natural mineral water which was underwent subtle energetic changes at the natural energetic deposit. Design: An estimation of protective efficiency of naturally modified mineral BAE SL water was performed on white outbred mice-males in models of H7N9 virus. The animals were monitored during 16 days after infection, and survived and fallen mice were counted daily. Results: The results revealed significant effect of the investigated preparation as possible prophylactic care and medical remedy to the mentioned virus. This means that one can be considered as potential effective remedy for human. Conclusions: As significant effect of the immune system resistance was revealed, the experimental model with studied naturally modified mineral water is potentially generalizable.

\section{Keywords}

H7N9 Virus, Flue, Protection Activity, Immune System, Subtle Energy, Treatment

\section{Introduction}

From the birth the person is surrounded by the environment sated with bacteria, viruses and other microbes- 
from inhaled air to drinking water and food. Till a certain moment the person with them coexists safely, however at a certain stage, when weakening protective functions of an organism is happens, there is a failure-the person gets sick.

Protection of the human body system provides two different types of immunity: inherent and acquired. Inherent immunity represents the resilience to bacteria given to the person from the birth. The acquired immunity develops during life, in process of acquaintance of an organism to these or those pathogenic microbes and viruses. The immune system remembers each meeting with a bacterium or a virus. Therefore it is capable to develop and use at any time the substances necessary for destruction of the specific enemy if one again intrudes in an organism.

The big problem is represented by the new and mutating viruses which recognition in immune system isn't significant or isn't available at all. Immune reactions (due to mainly protective proteins-immunoglobulins) allow to destroy got to an organism viruses. However, these processes are much more problematic if the immune system faces new type of a virus.

For this reason, it is so important to distinguish probable distribution of new types of viruses and to increase organism resistance to a possible meeting with them.

One of potentially dangerous problems for a human organism is the new strain of a virus of bird flu-A/H7N9. Influenza A (H7N9) belongs to one of subgroups of flu viruses which usually circulate among birds.

Until recently, this virus has not been observed in humans. The first reports of infection with a novel virus group A-the virus H7N9 - appeared in March 2013. Infected people, the people of China, suffered from severe pneumonia and acute respiratory distress syndrome. According to the WHO in May 2013, there have been 132 cases of infection with the new virus, the death toll reached 37.

Therefore, it is obvious that development of natural preparations for strengthening of immune system for improving of protective activity of an organism to arising new viruses is now actual.

One of such preparations is BAE Synergy Liquid (BAE SL) which is representing a water solution of a complex of microelements (silicon, aluminum, magnesium, calcium, iron, manganese, nickel, the titan, chrome, copper, silver, zinc, strontium, sodium, chlorine, sulphate-ion) which with the purpose of giving to one biological activity is activated by a special energetic source.

According to developers stimulates exchange processes and raises physical activity and working capacity of people, and also possesses antimicrobic action in the in vitro experiments [1] [2].

An experiment was conducted to determine the protective activity of the BAE Synergy Liquid preparation to anthrax and influenza A virus (H3N2) on white mice. Results showed a significant effect of the preparation as a preventive and therapeutic agent for these viruses [3] [4].

Other successful experiments with the preparations containing BAE Synergy Liquid were also obtained [5].

In this regard, it was of interest to assess its efficacy in infectious disease that occurs on the background of the impact of influenza A (H7N9). This was the focus of this study.

\section{Materials and Methods}

The research was conducted on white outbred mice-males with weighted 20 - 38 grams, obtained from the "Rappolovo" nursery of the Russian Academy of Medical Sciences. There was 200 animals have been taken in the research. The mice were on the 10 days quarantine before the beginning of experiment.

Mice were preliminary divided on four groups (3 experimental and control) on 50 animal units in each one.

Animals of experimental groups 1 and 2 have taken BAE SL preparation during 16 days before infection. Animals of control group and experimental group 3 drank the water without preparation. The preparation applied to animals together with potable water in 1:100 solution (animals drank independently from drinking bowls).

The mice in the first group took the BAE SL preparation before and after infection (experimental group 1). Animals of the second group received preparation only prior to infection (experimental group 2). Animals of the third group received preparation only after infection (experimental group 3).

Mice from the control group received drinking water without adding BAE SL preparation.

The flu virus has been simulated by subcutaneous injection in animal influenza virus A/H7N9.

The suspension of the agent was injected to animals unitary hypodermically in volume of $0.5 \mathrm{ml}$, with contaminating dose was $3.5 \mathrm{LD}_{50}$. With reference to each agent the $\mathrm{LD}_{50}$ value was defined on white outbred mice 
with calculation of this criterion by the Kerber method in Ashmarin I.P. and Vorobiev A.A. modification.

The protective effect of the preparation was assessed by mortality of mice in three experimental and control groups. Infected mice were observed for 16 days.

Statistical analysis was performed with the help of Statistica 6.0 program. The samples differed from each other by categories "alive" or "dead", so, for analysis the nonparametric criteria were used. The Sign Test and Wilcoxon Matched Pairs Test were applied.

\section{Results}

In experimental group 1 upon termination of observation period the percent of a lethality made only $52 \%$ (26 of 50); in experimental group 2 this percent made 62\% (31 of 50); in experimental group 3 this percent made 66\% (33 of 50); in control group the percent of a lethality made 82\% (41 of 50) (Figure 1, Table 1).

It should be noted that the greatest rate of all the surviving mice belongs to group 1 (35\%) that makes more than third part of all survivors (Figure 2). At the same time, the rate of the survived mice accepting BAE SL in any type of options makes $86 \%$ from all survived animals.

The ratio of survival in groups where mice took the BAE SL and did not take one differs by more than 6 times.

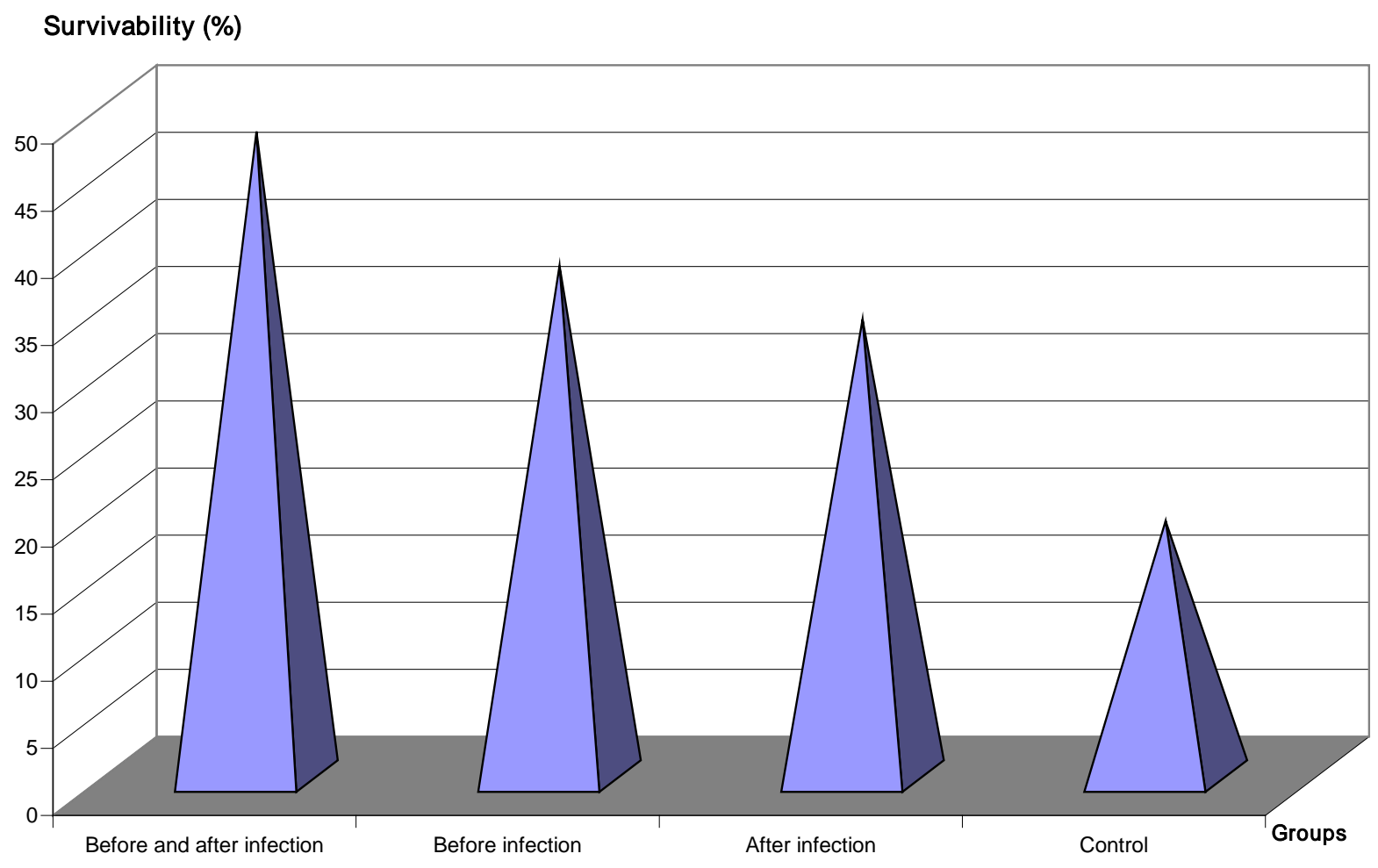

Figure 1. The survival rate in each group for all experimental and control groups.

Table 1. Protective resistance "BAE SL" preparation to the influenza virus A/H7N9 for all experimental and control groups.

\begin{tabular}{|c|c|c|c|c|}
\hline Groups of mice & $\begin{array}{l}\text { The number of } \\
\text { individuals in the group }\end{array}$ & $\begin{array}{c}\text { Mode of } \\
\text { preparation use }\end{array}$ & $\begin{array}{l}\text { The dose of } \\
\text { infection, } L D_{50}\end{array}$ & $\begin{array}{c}\text { The ability to } \\
\text { survive, \% }\end{array}$ \\
\hline Experimental 1 & 50 & Before and after infection & 3.5 & 48 \\
\hline Experimental 2 & 50 & Before infection & 3.5 & 38 \\
\hline Experimental 3 & 50 & After infection & 3.5 & 34 \\
\hline Control & 50 & Not used & 3.5 & 19 \\
\hline
\end{tabular}


The difference in the dynamics of lethality in the two treatment groups was not significant (Figure 3) in the first 10 days after infection. After that in observation period lethality stopped in the experimental group 1 while in the experimental group 2 mice continued to die. In the control group of mice lethality has obvious negative trend. Most impaired mice died in amount of 16 (32\%) during first two days after virus inoculation.

\section{Discussion}

For the experimental results was shown that the greatest statistically significant differences were observed between the first experimental group and control one by the Sign Test (Table 2), and Wilcoxon Matched Pairs Test (Table 3). At the same time, these same criteria shown the significance in comparing all other experimental groups between themselves and compared with the control group (Tables 4-12).

The smallest difference (with statistically significance) observed when comparing the groups 1 and 2 (Table 4), which is apparently due to the nature of survival in background of prophylactic use. All comparisons were carried out with tests of significance of $5 \%$ (Tables 6-8).

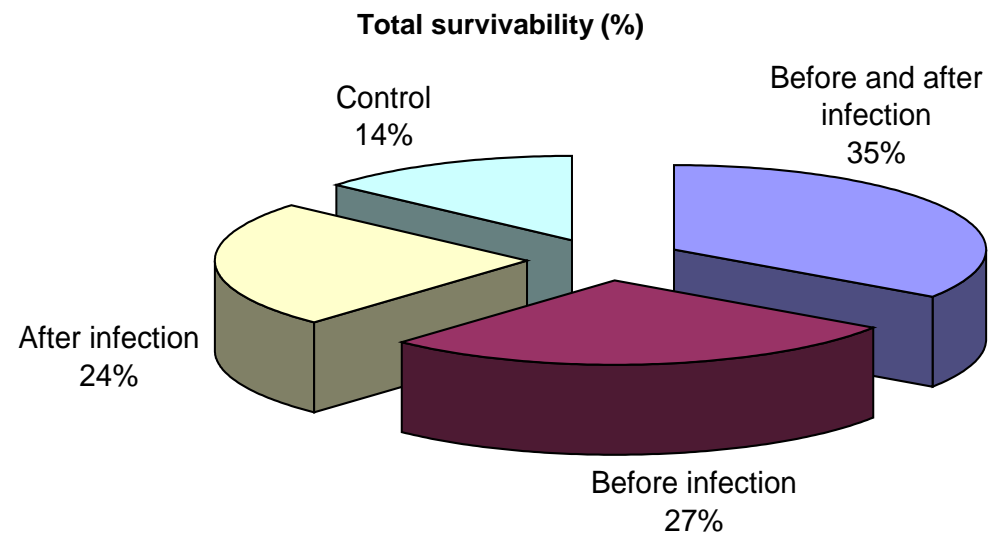

Figure 2. Survivability in each group.

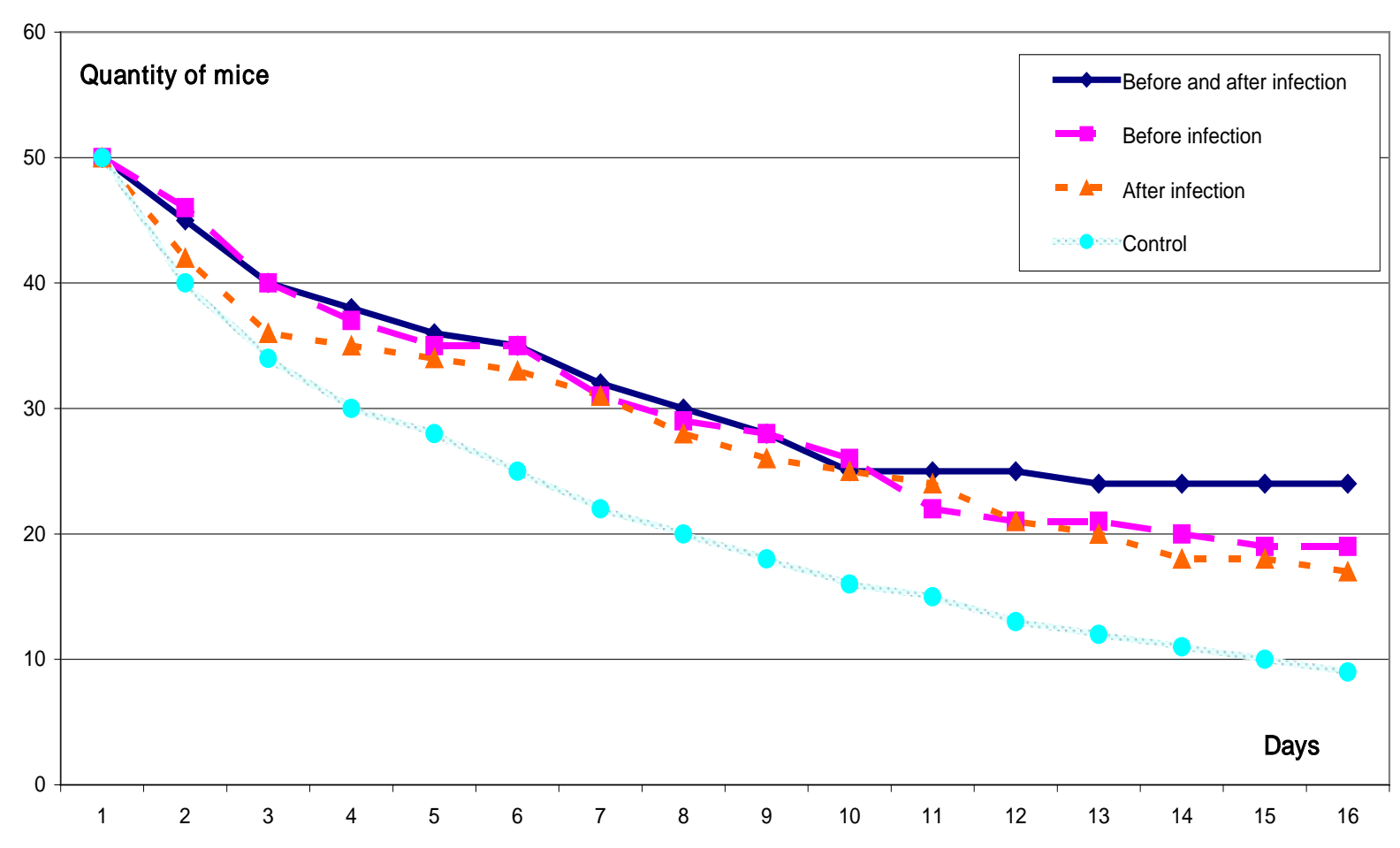

Figure 3. The dynamics of lethality of mice infected with influenza virus A/H7N9. 
Table 2. Sign test to compare the results on the first experimental and control groups.

\begin{tabular}{c|cccc}
\hline Groups of mice & $\begin{array}{c}\text { The number of individuals } \\
\text { in the group }\end{array}$ & $\begin{array}{c}\text { Mode of } \\
\text { preparation use }\end{array}$ & $\begin{array}{c}\text { The dose of } \\
\text { infection, } \mathbf{L D}_{\mathbf{5 0}}\end{array}$ & $\begin{array}{c}\text { The ability to } \\
\text { survive, \% }\end{array}$ \\
\hline Experimental 1 & 50 & Before and after infection & 3.5 & 48 \\
Experimental 2 & 50 & Before infection & 3.5 & 38 \\
Experimental 3 & 50 & After infection & 3.5 & 34 \\
Control & 50 & Not used & 3.5 & 19 \\
\hline
\end{tabular}

Table 3. Wilcoxon matched pairs test for comparison of the results on the first experimental and control groups.

\begin{tabular}{lcccc}
\hline & No. of & Percent & Z & p-Level \\
\hline Before and after infection \& control & 15 & 0.00 & 3.614 & 0.000301 \\
\hline
\end{tabular}

Table 4. Wilcoxon matched pairs test for comparison of the results for the first and second experimental groups.

\begin{tabular}{cccccc}
\hline & No. of & Percent & Z & p-Level \\
\hline Before and after infection \& before infection & 12 & 16.66 & 2.02 & 0.043308 \\
\hline
\end{tabular}

Table 5. Wilcoxon matched pairs test for comparison of the results on the first and third experimental groups.

\begin{tabular}{cccccc}
\hline & No. of & Percent & Z & p-Level \\
\hline Before and after infection \& after infection & 14 & 0.00 & 3.474 & 0.000512 \\
\hline
\end{tabular}

Table 6. Sign test to compare the results on the first and third experimental groups.

\begin{tabular}{ccccc}
\hline & Valid & T & Z & p-Level \\
\hline Before and after infection \& after infection & 16 & 0.00 & 3.295 & 0.000982 \\
\hline
\end{tabular}

Table 7. Wilcoxon matched pairs test for comparison on the results for the second and third experimental groups.

\begin{tabular}{|c|c|c|c|c|}
\hline & No. of & Percent & $\mathbf{Z}$ & p-Level \\
\hline Before infection \& after infection & 13 & 7.692 & 2.773 & 0.005546 \\
\hline
\end{tabular}

Table 8. Sign test to compare the results on the second and third experimental groups.

\begin{tabular}{lccccc}
\hline & Valid & $\mathbf{T}$ & $\mathbf{Z}$ & p-Level \\
\hline Before infection \& after infection & 16 & 8.5 & 2.585 & 0.009717
\end{tabular}

Table 9. Wilcoxon matched pairs test for comparison of the results on the second experimental and control groups.

\begin{tabular}{ccccc}
\hline & No. of & Percent & Z & p-Level \\
\hline Before infection \& control & 15 & 0.00 & 3.614 & 0.000301 \\
\hline
\end{tabular}

Table 10. Sign test to compare the results on the second experimental and control groups.

\begin{tabular}{lcccc}
\hline & Valid & T & P & Level \\
\hline Before infection \& control & 16 & 0.00 & 3.408 \\
\hline
\end{tabular}


Table 11. Wilcoxon matched pairs test for comparison of the results on the third experimental and control groups.

\begin{tabular}{ccccc}
\hline & No. of & Percent & Z & p-Level \\
\hline After infection \& control & 15 & 0.00 & 3.61 & 0.0003 \\
\hline
\end{tabular}

Table 12. Sign test to compare the results on the second experimental and control groups.

\begin{tabular}{ccccc}
\hline & Valid & $\mathbf{T}$ & $\mathbf{Z}$ & p-Level \\
\hline After infection \& control & 16 & 0.00 & 3.407771 & 0.000655 \\
\hline
\end{tabular}

\section{Conclusions}

- The ratio of survival in groups where mice took the BAE SL (under $3.5 \mathrm{LD}_{50}$ injection dose of infection of influenza virus A/H7N9) with and did not take one differs by more than 6 times (during 16 days observation).

- The most significant effect of the immune system resistance to viruses achieved with regular use of preparation solution BAE SL in the preventive and curative purposes (simultaneously).

- The preparation BAE Synergy Liquid at the preventive and curative scheme (separately) applications stimulates resistance of immune system of an organism of mice to influenza virus A/H7N9.

- Preventive use of the BAE SL preparation solution tends to increase survival ability of mice at $3.5 \mathrm{LD}_{50}$ injection dose of infection of influenza virus A/H7N9.

- Application only for therapeutic purposes increases resistance to influenza A, but not statistically significant. Perhaps statistical significance can be shown on a large sample of animals or the use of other proportions of the BAE SL solution.

- The most effective is a combination of preventive and curative schemes for the application of the solution of the BAE SL solution. This survival rate of mice in this group increased to 2.67 times in 16 days compared to control group.

\section{Acknowledgements}

We thank the staff of BAE International Inc. for their participation in this study, Mr. F. K. Lim, director of BAE International Inc., for his continued support of scientific study of BAE.

\section{References}

[1] Krizhanovsky, E.V., Lim, K.C. and Tan, S.C. (2005) Influence of Energetic Water on the Quality of Life. Journal of Food Agriculture and Environment, 3, 351-354.

[2] Krizhanovsky, E.V. and Lim, K.C. (2005) Influence of Subtle Energetic Change in Water on the Human Energy State. Journal of Subtle Energies \& Energy Medicine, 15, 147-161.

[3] Krizhanovsky, E.V. and Lim, K.C. (2008) Estimation of Naturally Modified Mineral Water Protection Activity against Experimental Infections. American Journal of Agricultural and Biological Science, 3, 399-402. http://dx.doi.org/10.3844/ajabssp.2008.399.402

[4] Krizhanovsky, E.V., Tursunova, K.B., Lim, K.C., et al. (2009) The Hypoglycemic Properties of BAE Maca Max Preparation. Online Journal of Biological Sciences, 9, 17-20. http://dx.doi.org/10.3844/ojbsci.2009.17.20

[5] Sviridov, L.P., Krizhanovsky, E.V., et al. (2006) The Study of the Antibacterial Efficacy of the "Micro" Preparation on Experimental Model of Anthrax Infection. Proceedings of the Congress "Infectious Diseases: Public Health Issues and Military Medicine, Saint-Petersburg, 22-24 March 2006, 24-28. 